\title{
Exercise-induced pain, stiffness, and tubular aggregation in skeletal muscle
}

\author{
ROGER A BRUMBACK, R DENNIS T A TON, \\ AND MARSHA E SUSAG \\ From the Neurology and Psychiatry Service and Neuromuscular Pathology Laboratory, \\ Veterans Administration Medical Center and Department of Neuroscience School of Medicine, \\ University of North Dakota, Fargo, North Dakota
}

S UMMARY The case is described of a 36 year old man with exercise-induced pain, stiffness, and tubular aggregation in skeletal muscle. Persistent CPK elevation and a normal forearm ischaemic exercise test were demonstrated. Electromyography was normal. Muscle biopsy showed aggregates of tubular structures in most fibres by histochemical and ultrastructural analysis. A relationship of this syndrome to known defects in muscle energy metabolism is postulated.

Two diseases of exercise-induced muscle pain and stiffness have defined metabolic defects (myophosphorylase deficiency and phosphofructokinase deficiency). ${ }^{1-6}$ In both of these conditions, painful muscle stiffness and cramping follow repeated muscle contraction. In each disease there is: (1) reduced muscle lactate production with exercise (forearm ischaemic exercise test); (2) elevated serum CPK at rest, with further elevation following exercise; (3) markedly reduced muscle fibre anaerobic glycolysis; and (4) tubular aggregation associated with marked degeneration of type-II muscle fibres. ${ }^{1-10}$ Iodoacetate inhibition of the glycolytic enzyme glyceraldehyde-3-phosphate dehydrogenase produces similar findings in experimental animals. ${ }^{11} 12$

Other less well-defined defects in muscle glycolytic enzyme systems, associated with exercise-induced pain, have been described..$^{13-19} \mathrm{We}$ report a case of a syndrome first described by Morgan-Hughes et $a l^{20}$ in which exercise-induced muscle pain is associated with tubular aggregates in affected muscle fibres.

\section{Case report}

A 36 year old white male, was studied for exerciseinduced muscle pain and stiffness. His birth and early

Address for reprint requests: Dr Roger A Brumback, VA Medical Center, Fargo, North Dakota 58102, USA.

Accepted 22 October 1980 development were normal. He was active in athletics throughout his school years. His symptoms began insidiously at about age 20 years, when he noted calf pain and stiffness with walking (particularly after prolonged Marine Corps guard duty). Initially, this pain and stiffness would disappear after a brief rest. Over the next several years pain and stiffness occurred with lesser degrees of activity, involved all the lower extremity musculature and resolved more slowly with rest (sometimes requiring up to 36 hours for resolution). By age 23 years he was experiencing symptoms in legs, hips, arms, back and neck. During the next 13 years he experienced progressively worsening pain and stiffness with exercise and marked reduction in his exercise tolerance. By age 30 years he would develop severe back and leg pain and stiffness after walking only one to two blocks. Standing for 15-20 minutes would result in back pain and stiffness. During the two years prior to our study he experienced pain and stiffness with such activities as walking up a flight of stairs or writing a single page. For three months he took occasional small doses of aspirin and diazepam, but took no medication for the four months prior to his initial evaluation and first muscle biopsy. $\mathrm{He}$ did not experience fasciculations or tremors. He had no pigmenturia. He had no alcoholic intake. There was no family history of neuromuscular disease.

General and neurological examination was normal except for a mild genu varus deformity bilaterally. His muscles were firm and non-tender to palpation. No percussion myotonia was elicited. There was no muscle weakness. Multiple investigations were normal, including: serum electrolytes, serum calcium, urinary creatinine clearance, serum total protein and protein 
electrophoresis, rheumatoid factor, fluorescent antinuclear antibody, cryoglobulins, serum thyroxine, serum alkaline phosphatase, SGOT, SGPT, and LDH. Examination of a 24-hour urine collection for uroporphyrins, coproporphyrins, porphobilinogens and urobilinogens was normal. There was persistent serum CPK elevation of $1 \frac{1}{2}$ times normal at rest, with further increase of serum $\mathbf{C K}$ to twice normal after exercise. During a glucose tolerance test, his blood sugar rose to $102 \mathrm{mg} / \mathrm{dl}$ from a fasting level of $92 \mathrm{mg} / \mathrm{dl}$, while his serum potassium did not significantly change from the fasting value of $4.0 \mathrm{mEq} / \mathrm{l}$. With the forearm ischaemic exercise test, 68 the patient developed no stiffness or cramp after 90 seconds of exercise and the serum lactate rose normally from a pre-exercise level of $8.7 \mathrm{mg} / \mathrm{dl}$ to $20.3 \mathrm{mg} / \mathrm{dl}$ three minutes postexercise. Potassium loading produced no symptoms. Electromyography of the deltoid, biceps brachii, rectus femoris, and gastrocnemius was normal.

\section{Muscle pathology}

Muscle biopsies were obtained (on two occasions one year apart) under local anaesthesia from the left biceps brachii muscles. Muscle specimens were freshfrozen for histochemistry (fig 1) or fixed in glutaraldehyde for electron microscopy (fig 2). In the sections stained with the modified Gomori trichrome stain, over $25 \%$ of the muscle fibres in any particular cross section contained bright red staining subsarcolemmal material. With serial sectioning, it was possible to demonstrate involvement of different fibres at different levels. This same accumulated material stained basophilic with haematoxylin and eosin. A rare degenerating fibre or small angular fibre was evident. The abnormal accumulations also stained dark blueblack in sections stained with adenylate deaminase, ${ }^{21}$ Sudan black B, toluidine blue, glyceraldehyde-3phosphate dehyrogenase-tetrazolium reductase, DPNH-tetrazolium reductase, TPNH-tetrazolium reductase, and menadione-linked alpha-glycerophosphate dehydrogenase. The accumulations were reddish with the periodic acid-Schiff (PAS) stain and maintained PAS-positive staining after diastase digestion. The accumulations were stained reddish-orange with the non-specific esterase. With SDH-tetrazolium reductase, alizarin red-S, phosphorylase, alkaline phospha-
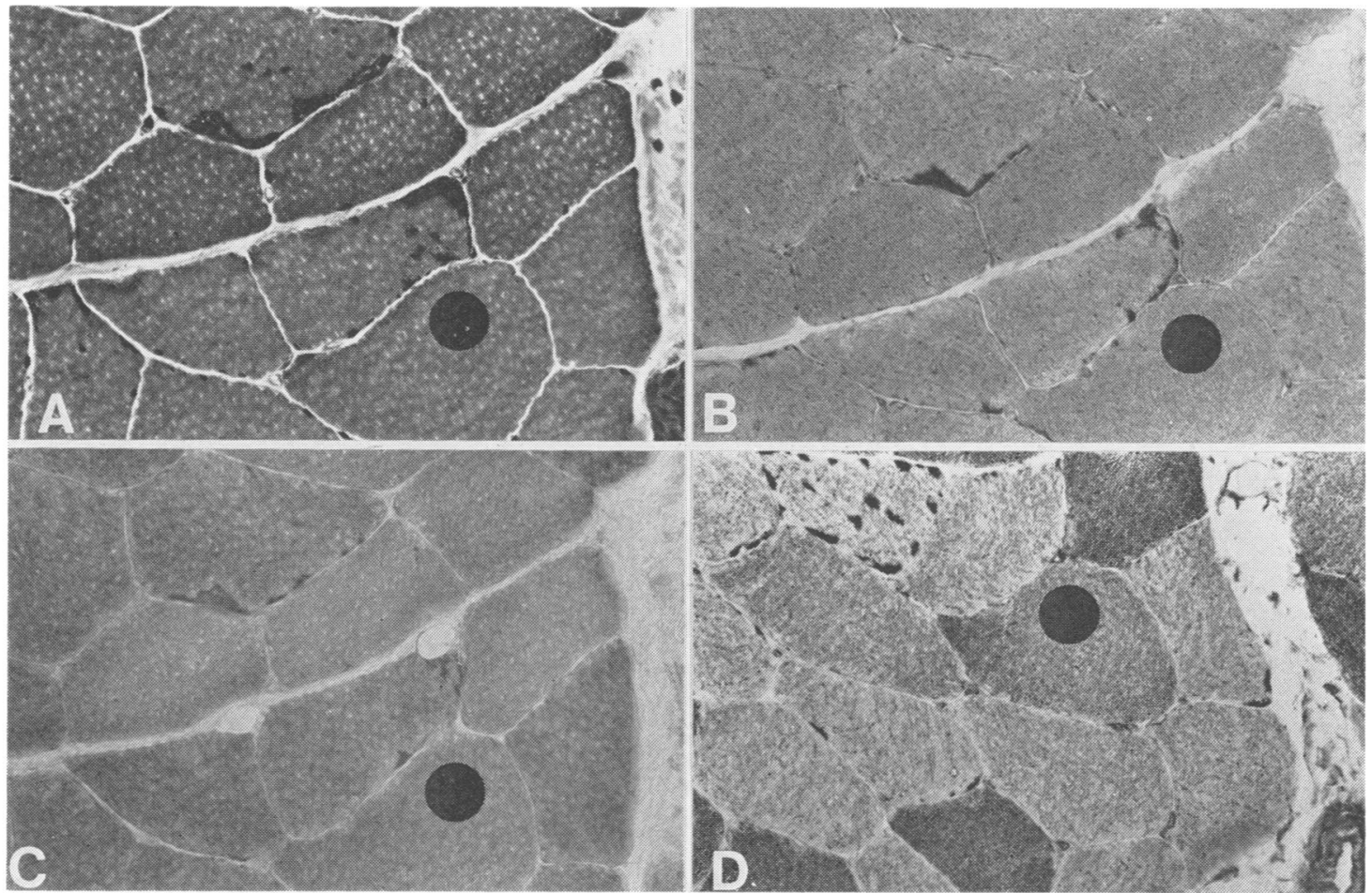

Fig 1 Low power photomicrographs of serial sections of left vastus lateralis muscle biopsy showing subsarcolemmal tubular aggregates (dot marks same fibre in each section). Note involvement of different fibres and different parts of same fibre at different levels. $\times 240$. A. Reddish staining of tubular aggregates with modified Gomori trichrome. B. Dark blue-black stained tubular aggregates with adenylate deaminase. C. Purple-black staining of tubular aggregates with menadione-linked alpha-glycerophosphate dehydrogenase. D. Dark blue-black staining of tubularaggregates with DPNH-TR. 

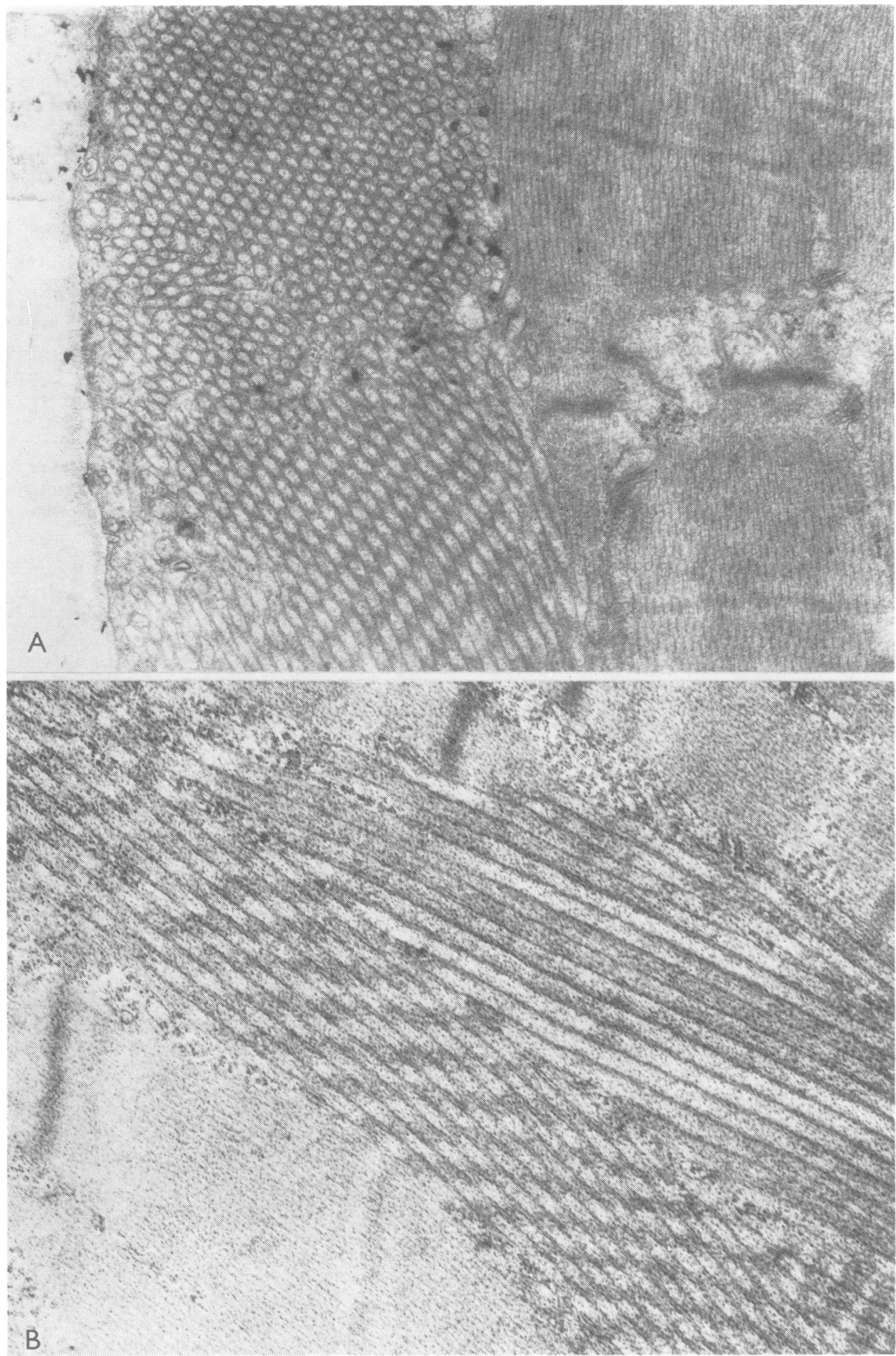

Fig 2 Electron microscopic photographs of subsarcolemmal tubular aggregates from left vastus lateralis muscle biopsy. A. $\times 7700 ; B . \times 13000$. 
tase, and acid phosphatase the muscle fibres stained normally with no evidence of the accumulations. With both alkaline ( $\mathrm{pH} 9 \cdot 4)$ and acid-preincubated $(\mathrm{pH} \mathrm{4.3)}$ myofibrillar ATPase stains, the accumulations were identifiable as unsustained subsarcolemmal holes in type-II muscle fibres only.

Ultrastructural study (fig 2) revealed aggregates of tubular structures situated immediately beneath the plasma membrane. Tubules in these aggregates were randomly oriented. Tubules cut in cross-section contained a core of amorphous material surrounded by an inner membrane.

\section{Discussion}

Our patient and two previously described patients ${ }^{20}$ have presented with: (1) normal ischaemic lactate production with exercise-induced muscle pain and stiffness; (2) mildly elevated serum CPK; and (3) tubular aggregation in typeII muscle fibres with little histologically-evident muscle fibre degeneration. The tubular aggregates that have been reported as incidental findings in porphyria, periodic paralysis, and myotonic dystrophy ${ }^{23}$ appear relatively empty in crosssection under electron microscopy. In contrast, the tubular aggregates in our patient (fig 2) and reported by Morgan-Hughes (personal communication) contain an electron dense core.

We suggest that patients with this syndrome have a defect of skeletal muscle energy metabolism which causes type-II fibre tubular aggregation but does not destroy these fibres (as occurs with the tubular aggregation in myophosphorylase deficiency and phosphof ructokinase deficiency). Biochemical study of such patients should reveal a defect of energy metabolism which causes less severe impairment of cellular function than does deficient activity of myophosphorylase, phosphof ructokinase, or glyceraldehyde-3-phosphate dehydrogenase. Many different categories and degrees of muscle glucose/glycogen metabolic disturbance may exist, all characterised by the triad of exercise-induced stiffness, muscle pain, and tubular aggregation with varying degrees of associated muscle fibre degeneration and CPK elevation.

R W Leech, T P Freeman, and Ms Susan McKay provided valuable assistance. This study was supported by the Veterans Administration.

\section{References}

1 Rowland LP. Glycogen-storage diseases of muscle. In: Goldensohn ES, Appel SH, ed. Scientific Approaches to Clinical Neurology, Philadelphia: Lea and Febiger, 1977: 1692-1714.
2 Layzer RB, Rowland LP, Ranney HM. Muscle phosphof ructokinase deficiency. Archiv Neurol (Chicago) 1967; 16:455.

3 Tarui S, Okuna G, Ikura Y, Tanaka T, Suda M, Nishikawa M. Phosphof ructokinase deficiency in skeletal muscle. A new type of glycogenosis. Biochem Biophys Res Commun 1965; 19:517-23.

4 Pearson CM, Rimer D, Mommaerts WFHM. A metabolic myopathy due to absence of muscle phosphorylase. Amer J Med 1961; 30:502.

5 Schmid R, Mahler R. Chronic progressive myopathy with myoglobinuria. Demonstration of a glycogenolytic defect in the muscle. J Clin Invest 1959; 38:2044.

6 McArdle B. Myopathy due to defect in muscle glycogen breakdown. Clin Sci 1951; 10:13-35.

7 Brooks BR, Brumback RA, Rosenbaum RB, Engel WK. Triglyceride-mediated prevention of exercise-induced rhabdomyolysis in myophosphorylase deficiency. Neurology (Minneap) 1977; 27:379.

8 Kula RW, Brumback RA, Engel WK, Line BR. Ischemic contracture in muscle phosphorylase deficiency: Clinical scanning and histochemical and auto-radiographic studies. Neurology (Minneap) 1977; 27:401-2.

9 Korenyi-Both A, Smith BH, Baruah JK. McArdle's syndrome. Fine structural changes in muscle. Acta Neuropathol (Berl) 1977; 40:11-19.

10 Bertorini TE, Brumback RA, Kula RW, Engel WK. Electrophysiologic and histochemical observation in five patients with muscle phosphorylase deficiency (MPD). Transact Am Neurol Assoc 1977; 102:141-2.

11 Brumback RA, Kula RW, Engel WK. A model of defects in muscle glycogenolysis/glycolysis (GG/Gly). J Neuropath Exp Neurol 1977; 36: 596.

12 Brumback RA, Susag ME, Gerst JW. Animal model of human disease: Defective skeletal muscle glucose and/or glycogen metabolism. Am J Pathol 1980; 101:241-4.

13 Satoyoshi E, Kowa H. A myopathy due to glycolytic abnormality. Archiv Neurol (Chicago) 1967; 17:248.

14 Strugalska-Cynowska $M$. Disturbances in the activity of phosphorylase-b-kinase in a case of McArdle myopathy. Folia Histochem Cytochem (Krakow) 1967; 5:151.

15 Thomson WHS, McLaurin JC, Prineas JW. Skeletal muscle glycogenosis: An investigation of two dissimilar cases. J Neurol Neurosurg Psychiatry 1963; 26:60.

16 Holmes JM, Houghton CR, Woolf AL. A myopathy presenting in adult life with features suggestive of glycogen storage disease. $J$ Neurol Neurosurg Psychiatry 1960; 23:302.

17 Olivier L, Schulman K, Larner J. Myopathy associated with glycogen deposition resulting from generalized lack of amylo-1, 6-glucosidase. J Clin Res 1961; 9:243. 
18 Mrozek K, Niebroj-Dobosz I, Lazarowicz J. Miopiatia glikogenowa $\mathrm{z}$ prawdopdobnyn niedoborem fosfoheksoizomerazy. Neur Neurochir Pol T VII 1973; 23:267-71.

19 Karpati G, Carpenter S, Wolfe LS, Sherwin A. A peculiar polysaccharide accumulation in muscle in a case of cardioskeletal myopathy. Neurology (Minneap) 1960; 19:553.

20 Morgan-Hughes JA, Mair WGP, Lascelles PT. A disorder of skeletal muscle associated with tubular aggregates. Brain 1970; 93:873-80.
21 Fishbein WN, Armbrustmacher VW, Griffin JL. Myoadenylate deaminase deficiency: A new disease of muscle. Science 1978; 200:545-8.

22 Lewis PD, Pallis C, Pearse AGE. "Myofathy" with tubular aggregates. J Neurol Sci 1971; 13; 381-8.

23 Engel WK, Bishop DW, Cunningham GG. Tubular aggregates in type-II muscle fibres: Ultrastructural and histochemical correlation. J Ultrastruct Res 1970; 31:507-25. 